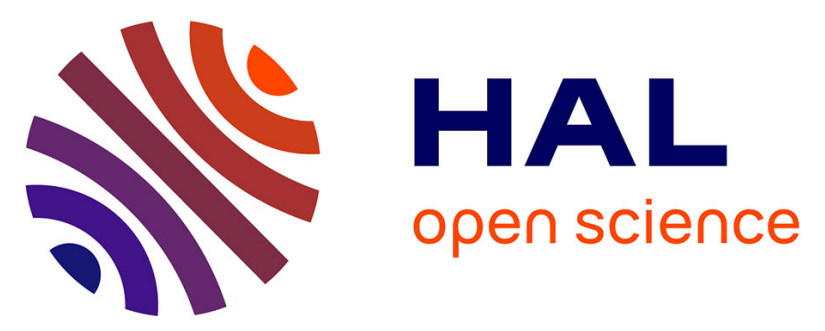

\title{
Design and photoinduced surface relief grating formation of photoresponsive azobenzene based molecular materials with ruthenium acetylides
}

Kichou N. Gherab, Rafik Gatri, Zakia Hank, Bernhard Dick, Roger-Jan

Kutta, Rainer Winter, Jérôme Luc, Bouchta Sahraoui, Jean-Luc Fillaut

\section{To cite this version:}

Kichou N. Gherab, Rafik Gatri, Zakia Hank, Bernhard Dick, Roger-Jan Kutta, et al.. Design and photoinduced surface relief grating formation of photoresponsive azobenzene based molecular materials with ruthenium acetylides. Journal of Materials Chemistry, 2010, 20, pp.2858-2864. 10.1039/B921450J . hal-00917141

\author{
HAL Id: hal-00917141 \\ https://hal.science/hal-00917141
}

Submitted on 11 Dec 2013

HAL is a multi-disciplinary open access archive for the deposit and dissemination of scientific research documents, whether they are published or not. The documents may come from teaching and research institutions in France or abroad, or from public or private research centers.
L'archive ouverte pluridisciplinaire HAL, est destinée au dépôt et à la diffusion de documents scientifiques de niveau recherche, publiés ou non, émanant des établissements d'enseignement et de recherche français ou étrangers, des laboratoires publics ou privés. 


\title{
Design and photoinduced surface relief grating formation of photoresponsive azobenzene based molecular materials with ruthenium acetylides $\dagger$
}

\author{
Kichou N. Gherab, ${ }^{a b d}$ Rafik Gatri, ${ }^{a c}$ Zakia Hank, ${ }^{d}$ Bernhard Dick, ${ }^{e}$ Roger-Jan Kutta, ${ }^{e}$ Rainer Winter, ${ }^{f}$ \\ Jérôme Luc, ${ }^{g}$ Bouchta Sahraoui ${ }^{g}$ and Jean-Luc Fillaut ${ }^{* a}$
}

\author{
Received 16th October 2009, Accepted 13th January 2010 \\ First published as an Advance Article on the web 16th February 2010 \\ DOI: $10.1039 / b 921450 j$
}

\begin{abstract}
Novel photoresponsive materials based on ruthenium(II) $\sigma$-acetylides coupled to an azobenzene moiety in the main $\pi$-conjugated chain have been synthesized. The introduction of a metal acetylide fragment in the same conjugated chain as the azobenzene induces the trans-cis-trans isomerization of the azo unit, while the rate of the thermal cis $\rightarrow$ trans back isomerization increases with increasing overall electron richness of these compounds. These azobenzene-containing ruthenium(II) acetylides show satisfactory processability and give rise to spin-coated uniform thin films. Formation of surface-relief gratings on their amorphous thin films and in a PMMA polymer matrix using a picosecond pulsed laser at $532 \mathrm{~nm}$ results in instantaneous inscription: saturation of the first order diffraction efficiency and of the modulation amplitude of gratings were obtained in less than $1 \mathrm{~s}$, while the orientation of these azodyes remains unchanged for up to 6 months.
\end{abstract}

\section{Introduction}

Photoresponsive molecular materials are currently attracting significant attention in relation to the emergence of molecular electronics. In particular, mechanical motions of azobenzenebased materials induced by photoirradiation have attracted a great deal of attention, because of the large structural rearrangement of the azo unit. In particular, photoinduced surface relief grating (SRG) formation observed for films of azobenzenebased materials, which is induced by mass transport upon interference exposure to coherent laser beams, is an attractive subject as one photomechanical effect. ${ }^{1}$

In this study, we show that ruthenium(II) acetylides containing an azobenzene moiety as a photochromic unit in the main $\pi$-conjugated system can constitute important components of molecular materials for electro-optic applications and for formation of surface relief gratings (SRGs) ${ }^{2}$ for optical information storage and photonic devices. ${ }^{3-6}$ Little attention has been given to the introduction of

${ }^{a}$ Sciences Chimiques de Rennes, UMR 6226 CNRS-Université Rennes 1 35042 Rennes, France.E-mail: jean-luc.fillaut@univ-rennes1.fr

${ }^{b}$ Centre de Recherche Scientifique et Technique en Analyses PhysicoChimiques, BP 248 Alger Rp, 16004 Alger, Algeria

${ }^{c}$ Laboratoire de Synthèse Organique et Hétérocyclique, Université de Tunis El Manar-B.P. 94 Poste Romena, 1068 Tunis, Tunisie

${ }^{d}$ Laboratoire d'Electrochimie - Corrosion, Métallurgie et Chimie Minérale, Faculté de Chimie, U.S.T.H.B, BP 32 El Alia, Bab-ezzouar, 16111 Alger, Algeria

${ }^{e}$ Institut für Physikalische Chemie der Universität Regensburg, D-93043 Regensburg, Germany

${ }^{f}$ Institut für Anorganische Chemie der Universität Regensburg, D-93043 Regensburg, Germany

${ }^{g}$ Département de Physique, Institut des Sciences et Technologies Moléculaires d'Angers, MOLTECH Anjou, UMR CNRS 6200, 49045 Angers Cedex 2, France

$\uparrow$ Electronic supporting information (ESI) available: Experimental procedures, and full synthesis and characterization of compounds 1a-3b. Text giving experimental procedures for SRG. See DOI: $10.1039 / \mathrm{b} 921450 \mathrm{j}$ a metal centre into azobenzene-containing organic systems for photomechanical effects, even if such an approach in order to form coordination or organometallic molecular materials allows extra parameters such as magnetism, colour and birefringence to be introduced. ${ }^{7}$ Besides, the metal centre can improve the electroluminescent properties of coordination molecular materials, ${ }^{\mathbf{8}, 9}$ or contribute to enhanced activity for non-linear optical applications. ${ }^{10}$

Photoreactions can be frequently deactivated when photochromes strongly interact with a metal complex. ${ }^{11}$ Meanwhile, strong metalto-ligand charge transfer (MLCT) ${ }^{12,13}$ may significantly impact on the kinetics of trans-cis photoisomerization in transition metal-based azo dyes. ${ }^{11,14,15}$ Our interest in azobenzene-functionalized metal acetylides came from the idea that the introduction of a metal acetylide fragment in the same conjugated chain as the azobenzene ${ }^{16,17}$ would induce the trans-cis-trans isomerization of the azo unit, considered as the rate-determining step for formation of SRGs. ${ }^{18}$ Alkynyl-metal complexes, which possess an almost linear $\mathrm{M}-\mathrm{C} \equiv \mathrm{C}-\mathrm{R}$ structure, can give rise to an efficient electronic coupling between the metal and the remote groups through the $\pi$-conjugated path, ${ }^{19}$ known as metal-to-ligand charge transfer (MLCT), depending on the degree of overlap between the filled metal d orbitals and the unoccupied $\pi$-orbitals of the alkynyl moiety. ${ }^{20}$

We report herein the synthesis and characterization of monoand bis-alkynyl bis(diphosphine)ruthenium complexes containing an azobenzene moiety in the main $\pi$-conjugated system. The photoinduced trans $\rightarrow$ cis isomerization and the thermal cis $\rightarrow$ trans back reisomerization of these compounds were studied in solution. We also describe the preparation of spin coated thin films based on these azo-functionalized metal acetylides and application to the formation of photoinduced surface relief gratings (SRGs). ${ }^{21}$

\section{Results and discussion}

Strong metal-to-ligand charge transfer (MLCT) has been reported to significantly impact on the kinetics of trans $\rightarrow$ cis 


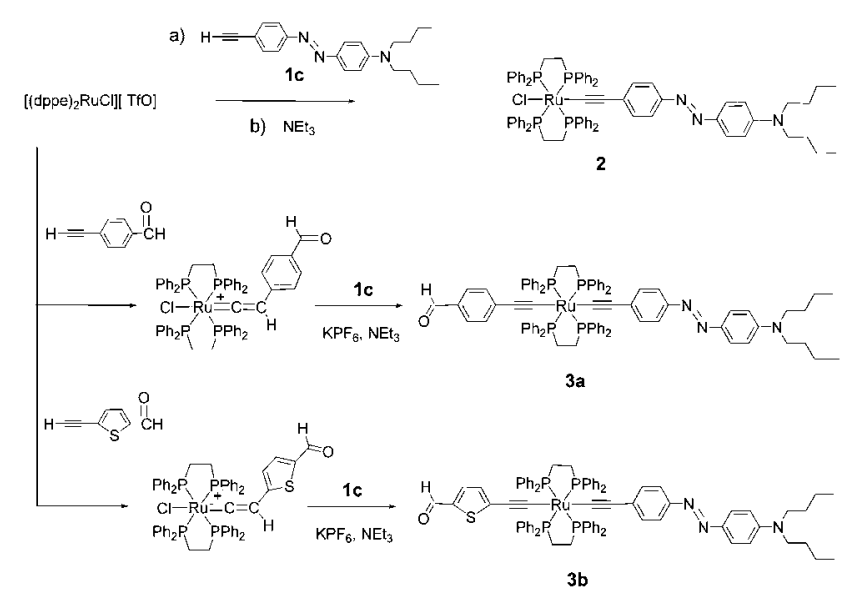

Scheme 1 Preparation of the investigated azobenzene containing ruthenium acetylides $\mathbf{2}$ and $\mathbf{3 a}, \mathbf{b}$.

photoisomerization in transition metal-based azo dyes. ${ }^{\mathbf{1 1 , 1 4 , 1 5}}$ Azobenzene-containing ruthenium(II) acetylide complexes $\mathbf{2}$ and 3a,b (Scheme 1) were thus designed in order to link together the metal alkynyl unit and the azobenzene system through the acetylide-containing conjugated $\pi$-system, as the introduction of a metal acetylide fragment in the same conjugated chain as the azobenzene was expected to favour the trans-cis-trans isomerization of the azo unit. The latter process is considered as the rate-determining step for formation of SRGs. ${ }^{18}$ Dialkyl amino groups at the termini of this azobenzene-based extended conjugated system were introduced to favour the processability of the resulting molecular materials.

The preparation of complexes $\mathbf{2}$ and 3a,b has been adapted from the well documented two steps procedure previously reported by Touchard and Dixneuf. ${ }^{22,23} 2$ was formed starting from $\left[c i s-(\mathrm{Cl})(\mathrm{dppe})_{2} \mathrm{Ru}\right][\mathrm{TfO}],{ }^{24,25}$ and $N, N$-dibutylamino-4ethynyl-azobenzene 1c, previously prepared from its bromo precursor $1 \mathbf{a}^{26}$ The complete formation of the intermediate vinylidene was monitored by ${ }^{31} \mathrm{P}$ NMR spectroscopy. This intermediate was washed with diethyl ether to remove the excess free acetylene before deprotonation with triethylamine. 3a,b were obtained by reacting 1c with the respective vinylidene species, ${ }^{27}$ previously prepared from $\left[\right.$ cis- $\left.(\mathrm{Cl})(\mathrm{dppe})_{2} \mathrm{Ru}\right][\mathrm{TfO}]$ and either 4-ethynyl benzaldehyde ${ }^{28}$ or 4-ethynyl thienyl carbaldehyde. ${ }^{27}$ Ruthenium acetylides $\mathbf{2}$ and 3a,b were purified by chromatography on silica gel using ether-pentane mixtures as eluents. $\mathbf{2}$ and 3a,b were obtained as red powders (100 mg scale) and fully characterized in solution (NMR, UV-visible spectrometry) and as powders (mass spectra and elemental analysis, thermal characterizations: TGA and DSC). The ${ }^{31} \mathrm{P}$ NMR spectra contain singlets, consistent with trans-ligated metal centres, the monoalkynyl complex 2 having a chemical shift of $50.5 \mathrm{ppm}$, and the bis-alkynyl complexes 3a,b resonating at ca. 54 ppm. ${ }^{13} \mathrm{C}$ NMR spectra were elucidated by using specific resonance sequences allowing the assignments of all carbon atoms of the extended systems. Full characterizations are provided in the ESI. $\dagger$

Thermogravimetric analysis (TGA) of compounds $\mathbf{2}$ and 3a,b in the temperature regime of 30 to $550{ }^{\circ} \mathrm{C}$ revealed that these compounds show high thermal stability with significant mass loss (approx. $40 \%$ ) at approximately $350{ }^{\circ} \mathrm{C}$. The glass transition temperatures of the new azobenzene containing compounds were investigated through differential scanning calorimetry (DSC): glass transition temperatures were evaluated in the range from 69 (2) to $79{ }^{\circ} \mathrm{C}(\mathbf{3 a}, \mathbf{b})$, obtained by DSC at $25 \mathrm{C} \mathrm{min}^{-1}$.

\section{Photochemical studies in solution}

The UV-vis spectra of all complexes contain broad non symmetrical absorption bands centred around $500 \mathrm{~nm},\left(2: \lambda_{\max }\right.$ $(\mathrm{nm})=495$; 3a: $\left.\lambda_{\max }(\mathrm{nm})=487,3 \mathbf{b}: \lambda_{\max }(\mathrm{nm})=484\right)$ $\left(\varepsilon \approx 40000(2)\right.$ to $\left.55000 \mathrm{M}^{-1} \mathrm{~cm}^{-1}(\mathbf{3 a}, \mathbf{b})\right)$ which are attributed to $\mathrm{d} \pi_{(\mathrm{Ru})} \rightarrow \pi^{*}{ }_{(\mathrm{C} \equiv \mathrm{CR})}$ metal-to-ligand charge transfers (ESI, Figure $\mathbf{S 3} \dagger$ ). ${ }^{29,30}$ These bands are accompanied by shoulders at 400 to $450 \mathrm{~nm}$ which can be consistent with the $\pi-\pi^{*}$ absorption bands ${ }^{1}$ of the azobenzene chromophore, as observed in 1c (Fig. 1a), that overlap with MLCT bands of the metalacetylide units.

The efficacy of photoinduced trans $\rightarrow$ cis isomerization was probed by irradiating cyclohexane solutions of alkyne 1c, and complexes $\mathbf{2}$ and 3a,b for $1 \mathrm{~s}$ at $460 \mathrm{~nm}$, close to the absorption maximum of the trans-isomers. Such irradiation time allows the
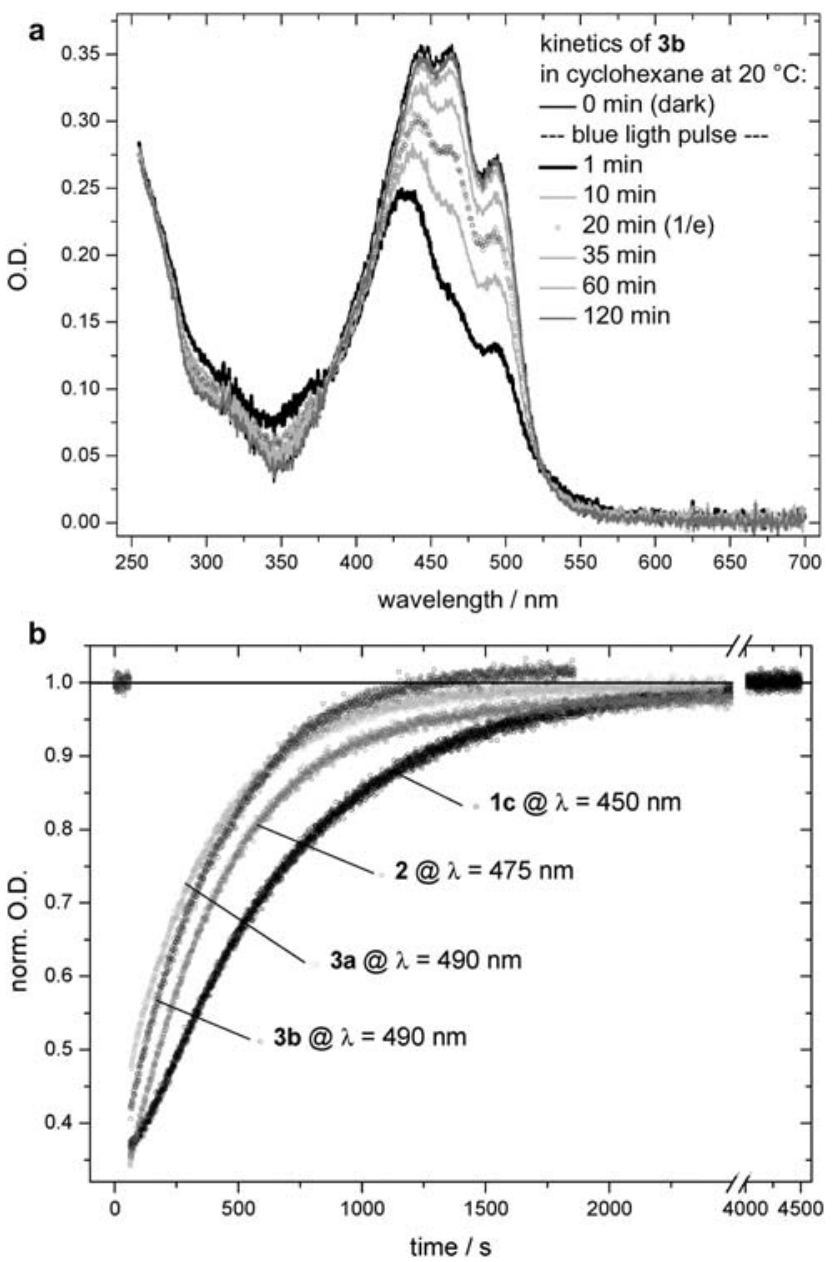

Fig. 1 (a) Spectra of $\mathbf{3 b}$ recorded at $20{ }^{\circ} \mathrm{C}$ in cyclohexane before and after irradiation for $1 \mathrm{~s}$ at $460 \mathrm{~nm}$, and kinetic measurements after specified period of time (from $1 \mathrm{~min}$ to $120 \mathrm{~min}$ in the dark. (b) Comparison of kinetic traces for the thermal reisomerization of photoirradiated azo compounds in cyclohexane. 
photo-stationary state to be reached, due to low optical densities (0.2-0.3). Upon irradiation, the absorption band of the ground state trans-isomer bleaches with a concomitant increase of the higher energy features of the $c i s$-isomer (Fig. 1a). When irradiation was stopped after the reaction system had reached the photostationary state, the electronic absorption spectrum gradually recovered to the original one due to the reverse cis-trans thermal isomerization. Meanwhile, we also observed during our attempts to monitor the thermal back reaction by following the change of the optical spectra with time, that the light intensity used for their recording had a remarkable influence on the apparent thermal isomerization rates, $i$. e. the cis $\rightarrow$ trans isomerization is also triggered by irradiation into the absorption bands of the cis-isomer. In order to minimize interference by photoactivated back-isomerization the kinetic traces were recorded monochromatically at the wavelength of maximum change within the band envelope for each studied species, as is indicated in Fig. 1b. The kinetic traces were satisfactorily fitted by a single exponential: the cis-trans isomerization reactions of 1c, 2 and 3a,b in cyclohexane follow first-order kinetics.

The results of this study are summarized in Table 1. Inspection of the data reveals that thermal isomerization rates of the ruthenium alkynyl complexes are slightly higher than for the parent alkyne. Considering that the $\mathrm{Cl}(\mathrm{dpppe})_{2} \mathrm{Ru}$ and $(\mathrm{ArC} \equiv \mathrm{C})(\mathrm{dppe})_{2} \mathrm{Ru}$ moieties are generally potent donors ${ }^{20,27,30,31}$ the reaction rate obviously increases with increasing overall electron richness, that is in the series $\mathbf{1 c}<\mathbf{3 b}<\mathbf{3 a}<\mathbf{2}$ (Table 1). This is in line with observations on other purely organic azobenzenes. $^{32}$

\section{Preparation and characterization of thin films}

Uniform thin films were prepared by spin coating from 2-10 wt $\%$ concentration solutions of $\mathbf{2}$ and $\mathbf{3 a}, \mathbf{b}$ in $\mathrm{CH}_{2} \mathrm{Cl}_{2}$ at room temperature. This procedure afforded films with good optical quality having a thickness ranging from 100 to $300 \mathrm{~nm} \pm 10 \mathrm{~nm}$, depending on the size of the glass support. SEM images show the high quality and homogeneity of the thin films as depicted in the ESI, Figure S2. $\uparrow$ The absorption spectra of the $300 \mathrm{~nm}$ thickness films have been registered on a Perkin Elmer Lambda 19 UV/VIS/NIR spectrometer and were compared to those of the $10^{-5} \mathrm{~mol} \mathrm{~L}^{-1}$ dichloromethane solutions of compounds 2 and 3a,b. No significant differences have been observed between the $\lambda_{\max }$ for thin layers and for solutions of compounds $\mathbf{2}$ and $\mathbf{3 a}, \mathbf{b}$.

\section{Surface relief grating formation using thin films of $2,3 a, b$}

Thin films containing chromophores based on azobenzene are known to respond mechanically to low power light interference, resulting in a transfer of an arbitrary optical pattern to surface

Table 1 Photophysical data on the thermal cis $\rightarrow$ trans back isomerization of the azo-compounds in cyclohexane

\begin{tabular}{ll}
\hline Compound & $1 / \mathrm{e}$ in s \\
\hline $\mathbf{2}$ & 394 \\
3a & 406 \\
3b & 428 \\
1c & 548 \\
\hline
\end{tabular}

relief in a single step, often well below the usual glass transition temperature. ${ }^{33}$ Spin coated thin films of pure compounds 2 and $\mathbf{3 a}, \mathbf{b}$ were thus studied in this context. Samples were illuminated by two light beams from a doubled frequency $(532 \mathrm{~nm}$, close to the absorption maxima of the complexes) pulsed $\mathrm{Nd}$ :YAG laser (Continuum Leopard D-10) using 16 ps pulses and working at $10 \mathrm{~Hz}$ repetition rate with $1-10 \mathrm{GW} \mathrm{cm}^{-2}$ intensity. These light beams are thus coincident with the broad absorption bands (from 400 to $600 \mathrm{~nm}$ ) of the chromophores 2 and $\mathbf{3}$. The gratings were characterized by diffraction efficiencies as well as by depth and shape of the surface modulation by AFM. In order to monitor the dynamics of gratings formation, a $\mathrm{He}-\mathrm{Ne} \mathrm{CW}$ reading laser with wavelength of $632.8 \mathrm{~nm}$ was used. The incidence angle of the two writing beams has been set to $\theta \approx 60^{\circ}$ in order to obtain a grating space equivalent to the wavelength of the writing beams $(\Lambda=\lambda / 2 \sin (\theta / 2) \approx 532 \mathrm{~nm})$.

Ultrafast formation of photoinduced surface relief gratings on films was observed as soon as the writing laser was switched on (Fig. 2). Noticeably, the diffraction spot remained stable until the next impulse, which provoked a new increase of the diffraction. This behaviour is consistent with the sequential orientation of molecules within the film. The complex $\mathbf{3 b}$ exhibits faster response than complexes $\mathbf{2}$ and $\mathbf{3 a}$ in all polarization states,

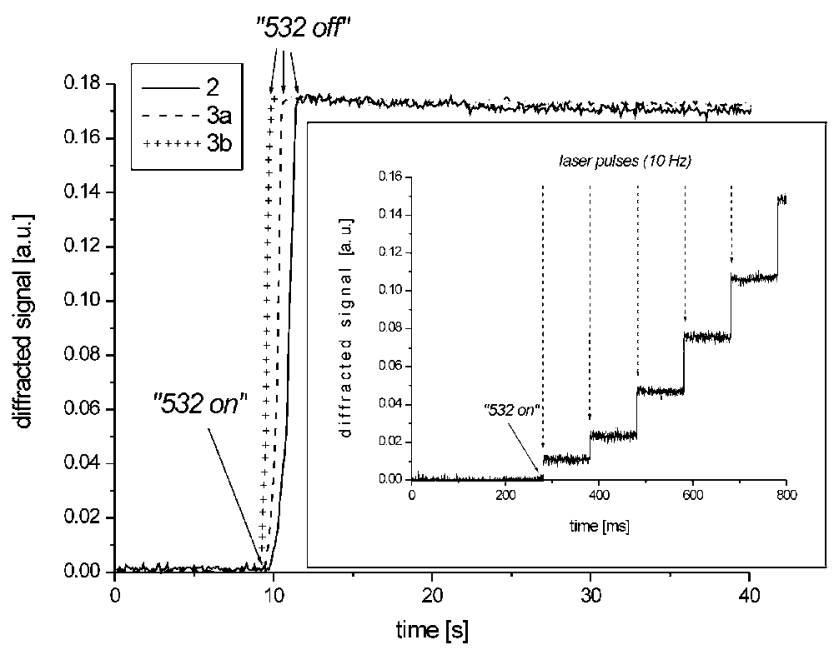

Fig. 2 Diffraction efficiency as a function of irradiation time for complexes $\mathbf{2}$ and 3a,b. The short time scale shows dynamics after each laser pulse.

Table 2 Values of writing times of gratings for different polarization states and for $t_{\text {imp }}=100 \mathrm{~ms}$ (repetition of laser pulses: $10 \mathrm{~Hz}$ ) of writing

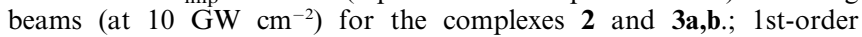
diffraction efficiency for different polarizations of writing beams (at $10 \mathrm{GW} \mathrm{cm}^{-2}$ )

\begin{tabular}{|c|c|c|c|c|c|c|}
\hline \multirow[b]{2}{*}{ State of polarization } & \multicolumn{3}{|c|}{$\begin{array}{l}\text { Inscription time/s } \\
( \pm 0.1 \mathrm{~s})\end{array}$} & \multicolumn{3}{|c|}{$\begin{array}{l}\text { Maximal diffraction } \\
\text { efficiency } \eta_{+1}(\%) \\
( \pm 0.1 \%)\end{array}$} \\
\hline & 2 & 3a & $3 \mathbf{b}$ & 2 & $3 \mathbf{a}$ & $3 \mathbf{b}$ \\
\hline$s-s$ & 1.8 & 1.4 & 0.7 & 8.5 & 10.2 & 12.7 \\
\hline$p-p$ & 3.0 & 2.4 & 1.3 & 5.6 & 8.5 & 10.9 \\
\hline$s-p$ & 46.9 & 35.8 & 19.4 & 1.3 & 2.8 & 4.0 \\
\hline
\end{tabular}




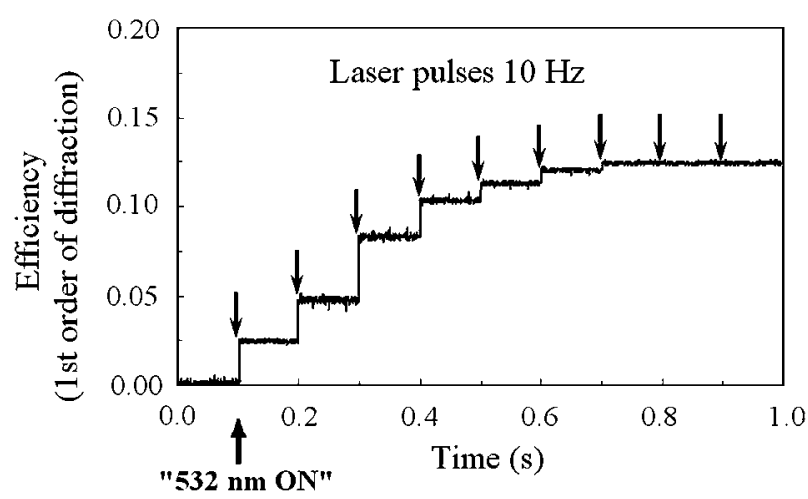

Fig. 3 Diffraction efficiency as a function of irradiation time for complex $\mathbf{3 b}$ for polarization $s-s$. The short time scale shows dynamics after each laser pulse.

which results in the highest diffraction efficiency (see Table 2: $12.7 \%$ ) and modulation amplitude $(100 \mathrm{~nm})$ for this complex $\mathbf{3 b}$ in $s$ - $s$ polarization state.

Longer writing times (in the range of 1.3 to $3.0 \mathrm{~s}$ ) were necessary for polarisation $p-p$, while the diffraction efficiency $(5.6-10.9 \%)$ and the modulation amplitude were lower. Finally, the polarisation $s-p$ gave a weaker and slower surface modulation. The observed differences for the various polarization states relate to preferential orientation of the chromophores along direction perpendicular to the substrate (Table 3).

The dynamics of diffraction grating's creation using amorphous thin films of the complexes $\mathbf{2}$ and 3a,b on the laser pulses illustrates the stability of the photo-induced reorientation of the molecules in the irradiated area (Fig. 3): after each laser pulse no decrease in the first order diffraction efficiency has been noticed, as it is often the case. ${ }^{34}$ It is thought that the molecules agglutinate into zones of low intensities where they remain frozen after each laser pulse. These motions would result in the observed protuberances of grating (AFM measurements) and occur until a completely static position is reached (saturation of the first order diffraction efficiency and the modulation amplitude of gratings). Better performances of $\mathbf{3 b}$ could be related with the better electronic conjugation in this compound, from one end to the other one, thanks to the presence of the thienyl bridge.

The diffraction efficiency measured in real time and the average modulation amplitude measured at different times by AFM microscopy followed a similar evolution as a function of the irradiation time. From AFM images, the estimated value of the laser spot diameter was $70 \mu \mathrm{m}$. It can also be deduced from AFM measurements that the surface relief gratings are written perpendicularly to the polarization direction of writing beams.

Table 3 Average modulation amplitudes for different polarizations of writing beams (at $10 \mathrm{GW} \mathrm{cm}^{-2}$ )

Average modulation amplitude/nm $( \pm 5 \mathrm{~nm})$

\begin{tabular}{llll}
\cline { 2 - 4 } State of polarization & $\mathbf{2}$ & $\mathbf{3 a}$ & $\mathbf{3 b}$ \\
\hline$s-s$ & 70 & 70 & 100 \\
$p-p$ & 40 & 70 & 90 \\
$s-p$ & 10 & 20 & 30 \\
\hline
\end{tabular}

Inscribed gratings showed excellent long-term stability: only a small decrease of the average modulation amplitude (less than $2 \%$ ) was observed when AFM images were performed after even more than six months on inscribed gratings conserved at ambient temperature and light. Lastly, the photo-induced SRGs were completely erased subjecting the thin films to a temperature close to $120{ }^{\circ} \mathrm{C}$, well beyond the glass transition temperatures.

\section{Surface relief grating formation using thin films of $2,3 a, b$ and DR1 in PMMA}

The dynamics of surface relief gratings formation for thin films of the chromophores $\mathbf{2}$ and $\mathbf{3} \mathbf{a}, \mathbf{b}$ were finally compared to that of Disperse Red 1 (DR1: $N$-ethyl- $N$-hydroxyethyl-4-(4'-nitrophenylazo)phenylamine) as a model in PMMA (in order to become filmogenic, DR1 necessitates to be introduced as a dopant in a matrix). This chromophore also shows a strong absorption band around $500 \mathrm{~nm}$ which is coincident with the writing beams at $532 \mathrm{~nm}$. Azo dye DR 1 and chromophores 2 and $\mathbf{3 a}, \mathbf{b}$ were similarly introduced as guest chromophores in $30 \%$ concentration by mass in polymethyl methacrylate (PMMA). The polymer and azo dyes (DR1, 2, 3a,b) were dissolved in chloroform, and spin coated on cleaned glass after it had been filtered with a $250 \mathrm{~nm}$ filter. The film thickness was estimated to be $300 \mathrm{~nm}$ for PMMA thin films of 2, 3a,b and $1400 \mathrm{~nm}$ for the DR1-PMMA model. Absorption bands ranged from 400 to $600 \mathrm{~nm}$, with absorption maxima around $500 \mathrm{~nm}$ (see the ESI $\dagger$ ).

The surface relief gratings have been inscribed on the polymer thin layers under the same experimental conditions as the gratings obtained for amorphous thin films of 2, 3a,b for different polarization states ( $s-s, p-p$ and $s-p$ ) of the writing beams. Noticeably, the PMMA matrix induced a decrease of the first order diffraction efficiency and of the modulation amplitude, and an increase of the writing times of SRGs for the doped polymers, in comparison with the amorphous thin films of pure complexes. On the other hand, higher diffraction efficiencies and faster kinetics were observed for the formation of grating of the PMMA doped polymers with the complexes $\mathbf{2}$, 3a or $\mathbf{3 b}$ in comparison with the DR1-PMMA model (Table 4). The observed differences cannot relate with the thickness of the studied films: it is known that the diffraction efficiency decreases considerably when the film thickness decreases. ${ }^{35}$

Whatever the complexes $\mathbf{2}$, 3a or $\mathbf{3 b}$, the PMMA matrix induces a decrease of the first order diffraction efficiency and of the modulation amplitude, and an increase of the writing times of SRGs for the doped polymers, in comparison with the amorphous pure thin films. For instance, the highest first order diffraction efficiency $(8.5 \%)$ and the shortest writing time of gratings $(0.8 \mathrm{~s})$ were obtained for the 3b-PMMA doped polymer in polarization $s-s$ (Table 4 ). These results suggest that the SRG inscription kinetics and rates depend on the effective concentration of the chromophores in the materials: the separation between neighbouring dye chromophores in amorphous films and between dye chromophores and polymer chains would dictate the kinetics and amplitude of the deformation of the film surface.

Higher diffraction efficiencies and faster kinetics observed for the formation of grating of the PMMA doped polymers with the complexes 2, 3a or $\mathbf{3 b}$ in comparison with the DR1-PMMA 
Table 4 Main characteristics for PMMA doped thin films with 2, 3a,b and DR1 for different polarization states of writing beams (at $10 \mathrm{GW} \mathrm{cm}^{-2}$ )

\begin{tabular}{|c|c|c|c|c|}
\hline \multirow[b]{3}{*}{ Polarization state } & \multicolumn{4}{|c|}{ Maximum diffraction efficiency $\eta_{+1}(\%)( \pm 0.1 \%)$} \\
\hline & \multicolumn{4}{|c|}{ Times of writing/s $( \pm 0.1 \mathrm{~s})$} \\
\hline & 2-РMМА & 3а-PMМА & 3b-PMМА & DR1-PMMA \\
\hline$s-s$ & $\begin{array}{l}5.1 \\
{[40]} \\
\{2.0\}\end{array}$ & $\begin{array}{l}6.9 \\
{[50]} \\
\{1.5\}\end{array}$ & $\begin{array}{l}8.5 \\
{[70]} \\
\{0.8\}\end{array}$ & $\begin{array}{l}2.1 \\
{[20]} \\
\{3.2\}\end{array}$ \\
\hline$p-p$ & $\begin{array}{l}2.7 \\
{[20]} \\
\{3.5\}\end{array}$ & $\begin{array}{l}5.5 \\
{[40]} \\
\{2.9\}\end{array}$ & $\begin{array}{l}6.8 \\
{[60]} \\
\{1.3\}\end{array}$ & $\begin{array}{l}1.3 \\
{[10]} \\
\{5.2\}\end{array}$ \\
\hline$s-p$ & $\begin{array}{l}\overline{[-]} \\
\{\}\end{array}$ & $\begin{array}{l}1.4 \\
{[10]} \\
\{36.5\}\end{array}$ & $\begin{array}{l}2.2 \\
{[20]} \\
\{22.6\}\end{array}$ & $\begin{array}{l}\overline{C-]} \\
\{\}\end{array}$ \\
\hline
\end{tabular}

model evidenced the specific efficiency of organometallic complexes 2, 3a and 3b. Participation of the strong $\mathrm{d} \pi_{(\mathrm{Ru})} \rightarrow$ $\pi^{*}{ }_{(\mathrm{C} \equiv \mathrm{CR})}$ MLCT which overlaps with the $\pi-\pi^{*}$ absorption transition of both trans- and cis-azobenzene chromophores may impact on the efficiency of the trans-cis-trans isomerization of the azo unit in these complexes. On the other hand, it is now established that trans-cis photoisomerization necessitates a pocket to be created around the azo moiety. ${ }^{36,37}$ We suggest then that an increased separation between neighbouring dye chromophores because of the sterically demanding bis(diphosphine)ruthenium units ${ }^{\mathbf{3 8}}$ in chromophores $\mathbf{2}, \mathbf{3 a}, \mathbf{b}$ could impact on the efficiency of trans-cis photoisomerization in the films and on the mass transport forces that result in surface deformations. Further studies are in progress to elucidate theses aspects.

\section{Conclusion}

In the present study, we have reported the design and the preparation of organometallic containing azobenzene-based photochromic amorphous molecular materials. Kinetic studies show that the thermal cis $\rightarrow$ trans back isomerization increases with increasing overall electron richness of these compounds. These azobenzene containing ruthenium-acetylide complexes show noticeable processability resulting in the formation of highquality thin films by spin coating and the relationship between molecular structure and SRG-forming properties was investigated. Ultrafast photoinduced surface relief gratings was observed. Interestingly, long term stability of the SRGs was also observed, recording of the films being maintained even after several months, at room temperature, without protecting them from ambient air. Comparative studies involving PMMA doped polymers with the complexes $\mathbf{2}, \mathbf{3 a}$ or $\mathbf{3 b}$ in comparison with the DR1-PMMA model also revealed the specific efficiency of the investigated organometallic complexes.

\section{Experimental}

\section{Synthesis and characterization of compounds 2 and 3a,b}

Synthesis of 2. In a Schlenk tube $\left[(\mathrm{dppe}){ }_{2} \mathrm{RuCl}\right][\mathrm{TfO}]^{24,25}$ (0.092 mmol, $100 \mathrm{mg})$ and 1c $(61.27 \mathrm{mg}, 0.18 \mathrm{mmol})$ were introduced under argon and dissolved in $10 \mathrm{ml}$ of freshly distilled dichloromethane. The resulting mixture was stirred at room temperature overnight. The completion of the reaction was monitored by ${ }^{31} \mathrm{P}$ NMR spectrometry $\left({ }^{31} \mathrm{P} \mathrm{NMR}\left(\mathrm{CH}_{2} \mathrm{Cl}_{2}+\right.\right.$ $\mathrm{CDCl}_{3}$ ): s, $38.9 \mathrm{ppm}$ ). The solvent was removed under reduced pressure and the solid residue was washed several times with diethyl ether, before being treated upon addition of a $10 \mathrm{ml}$ solution of $\mathrm{NEt}_{3}(0.2 \mathrm{ml})$ in DCM. Silica gel column chromatography (diethyl ether-THF $80: 20$ ) afforded 2 as a red-orange solid (100 mg, 77\% yield). ${ }^{1} \mathrm{H}$ NMR $\left(\mathrm{CDCl}_{3}, 300.133 \mathrm{MHz}\right.$, $297 \mathrm{~K}, \delta \mathrm{ppm}): 7.78(\mathrm{~m}, 2 \mathrm{H}), 7.67 \quad(\mathrm{~m}, 2 \mathrm{H}), \quad 7.62-6.78$ $(\mathrm{m}$, aromatics, $44 \mathrm{H}), 3.31(\mathrm{t}, 4 \mathrm{H}), 1.72-1.56(\mathrm{~m}, 4 \mathrm{H}), 1.40$ (m, 4H), $2.80\left(\mathrm{~m}, 8 \mathrm{H}, \mathrm{CH}_{2}\right.$ dppe), $1.03(\mathrm{t}, 6 \mathrm{H}) .{ }^{13} \mathrm{C}\left\{{ }^{1} \mathrm{H}\right\} \mathrm{NMR}$ $\left(\mathrm{CDCl}_{3}, 125 \mathrm{MHz}, 297 \mathrm{~K}, \delta \mathrm{ppm}\right): 150.0,149.0,143.6,136.3$ (qt, $\mid{ }^{1} J_{\mathrm{P}-\mathrm{C}}+{ }^{3} J_{\mathrm{P}-\mathrm{Cl}}=12 \mathrm{~Hz}, \mathrm{Cq}$, Cipso dppe phenyl), 135.7 (qt, $\left|{ }^{1} J_{\mathrm{P}-\mathrm{C}}+{ }^{3} J_{\mathrm{P}-\mathrm{C}}\right|=10 \mathrm{~Hz}, \mathrm{Cq}$, Cipso dppe phenyl), 134.5 (CH dppe phenyl), 134.2, 132.5 (q, $\left.{ }^{2} J_{\mathrm{P}-\mathrm{C}}=14.9 \mathrm{~Hz}\right), 131.8,130.5$, 130.2, 128.9, 127.3 and 127.0, 124.7, 121.8, 115.7, 111.2, 51.0, 30.7 (qt, $\mid{ }^{1} J_{\mathrm{P}-\mathrm{C}}+{ }^{3} J_{\mathrm{P}-\mathrm{C}}=23 \mathrm{~Hz}, \mathrm{CH}_{2}$ dppe), 29.6, 20.0, 14.1. ${ }^{31} \mathrm{P}\left\{{ }^{1} \mathrm{H}\right\}$ NMR $\left(\mathrm{CDCl}_{3}, 81 \mathrm{MHz}, 297 \mathrm{~K}, \delta \mathrm{ppm}\right): 49.2$ (s). Elemental Analysis: $\mathrm{C}_{74} \mathrm{H}_{74} \mathrm{~N}_{3} \mathrm{ClP}_{4} \mathrm{Ru}$ (1265.84): calcd: C 70.22, H 5.89, N 3.32; found: C 69.86, H 6.10, N 3.39 .

Synthesis of 3a. In a Schlenk tube $(0.138 \mathrm{mmol}, 150 \mathrm{mg})$ of $\left[(\mathrm{dppe})_{2} \mathrm{RuCl}\right][\mathrm{TfO}]$ and $(20 \mathrm{mg}, 0.152 \mathrm{mmol})$ of 4-ethynyl benzaldehyde ${ }^{28}$ were introduced under argon and dissolved in $10 \mathrm{ml}$ of freshly distilled and degassed dichloromethane. The resulting mixture was stirred at room temperature overnight. The completion of the formation of the vinylidene species was monitored by ${ }^{31} \mathrm{P}$ NMR spectrometry $\left({ }^{31} \mathrm{P} \mathrm{NMR}\left(\mathrm{CH}_{2} \mathrm{Cl}_{2}+\right.\right.$ $\mathrm{CDCl}_{3}$ ): s, $37.3 \mathrm{ppm}$ ). The solvent was removed under reduced pressure and the vinylidene was washed several times with diethyl ether to remove the excess of 4-ethynyl benzaldehyde. Then to the solid residue were successively added $1 \mathrm{c}(92 \mathrm{mg}, 0.18 \mathrm{mmol})$, (100 mg, $0.54 \mathrm{mmol})$ of $\mathrm{KPF}_{6}$ and $(0.24 \mathrm{mmol}, 34 \mu \mathrm{l})$ of triethylamine. The reaction mixture was allowed to stir for $16 \mathrm{~h}$, the formation of the final product being monitored by ${ }^{31} \mathrm{P}$ NMR. 3a was purified on a silica gel column chromatography (diethyl ether-THF $80: 20)$ and obtained as a red orange solid $(90 \mathrm{mg}$, $44 \%$ yield $).{ }^{1} \mathrm{H}$ NMR $\left(\mathrm{CDCl}_{3}, 300.133 \mathrm{MHz}, 297 \mathrm{~K}, \delta \mathrm{ppm}\right): 9.89$ (s, 1H, CHO), $7.91(\mathrm{~m}, 2 \mathrm{H}), 7.78-6.81(\mathrm{~m}, 50 \mathrm{H}), 3.28(\mathrm{t}, 4 \mathrm{H})$, 1.69-1.62 (m, 4H), $1.41(\mathrm{~m}, 4 \mathrm{H}), 2.23$ (m, $8 \mathrm{H}, \mathrm{CH}_{2}$ dppe), 
$1.02(\mathrm{t}, 6 \mathrm{H}) .{ }^{13} \mathrm{C}\left\{{ }^{1} \mathrm{H}\right\} \mathrm{NMR}\left(\mathrm{CDCl}_{3}, 125 \mathrm{MHz}, 297 \mathrm{~K}, \delta \mathrm{ppm}\right)$ : $191.3\left(\mathrm{C}_{26}\right), 150.0\left(\mathrm{C}_{10}\right), 149.3\left(\mathrm{C}_{6}\right), 148.3\left(\mathrm{q},{ }^{2} J_{\mathrm{p}-\mathrm{c}}=18.7 \mathrm{~Hz}\right)$, $143.5\left(\mathrm{C}_{7}\right), 136.8\left(\mathrm{qt},\left.\right|^{1} J_{\mathrm{P}-\mathrm{C}}+{ }^{3} J_{\mathrm{P}-\mathrm{C}}=11 \mathrm{~Hz}, \mathrm{Cq}\right.$, Cipso dppe phenyl), 136.7 (qt, $\left|{ }^{1} J_{\mathrm{P}-\mathrm{C}}+{ }^{3} J_{\mathrm{P}-\mathrm{C}}\right|=10 \mathrm{~Hz}, \mathrm{Cq}$, Cipso dppe phenyl), 134.2 (CH dppe phenyl), 134.1 (CH dppe phenyl), 137.0, 131.8, 131.1, 130.2, 129.5, 124.8, 122.1, 121.4, 119.2, 111.1, 110.4, 51.0, 29.5, 20.3, 14.1. ${ }^{31} \mathrm{P}\left\{{ }^{1} \mathrm{H}\right\} \mathrm{NMR}\left(\mathrm{CDCl}_{3}, 81 \mathrm{MHz}, 297 \mathrm{~K}\right.$, $\delta$ ppm): 54.5 (s). Elemental Analysis: $\mathrm{C}_{83} \mathrm{H}_{79} \mathrm{~N}_{3} \mathrm{OP}_{4} \mathrm{Ru}(1359.53)$ : calcd: C 73.33, H 5.86, N 3.09; found: C 73.36, H 6.13, N 3.41.

Synthesis of $\mathbf{3 b}$. The same procedure was used starting from (0.092 mmol, $100 \mathrm{mg})$ of [(dppe $\left.)_{2} \mathrm{RuCl}\right][\mathrm{TfO}]$ and $25 \mathrm{mg}$, $0.184 \mathrm{mmol}$ of 5-ethynylthiophene-2-carbaldehyde ${ }^{27}$ (vinylidene intermediate: $\left.{ }^{31} \mathrm{P} \mathrm{NMR}\left(\mathrm{CH}_{2} \mathrm{Cl}_{2}+\mathrm{CDCl}_{3}\right): \mathrm{s}, 37.1 \mathrm{ppm}\right)$, before adding $1 \mathrm{c}(60 \mathrm{mg}, 0.12 \mathrm{mmol}),(66 \mathrm{mg}, 0.36 \mathrm{mmol})$ of $\mathrm{KPF}_{6}$ and $(0.164 \mathrm{mmol}, 23 \mu \mathrm{l})$ of triethylamine. Compound $\mathbf{3 b}$ was obtained as a dark orange solid (50 mg, 36\% yield). ${ }^{1} \mathrm{H}$ NMR $\left(\mathrm{CDCl}_{3}\right.$, $300.133 \mathrm{MHz}, 297 \mathrm{~K}, \delta \mathrm{ppm}): 9.89$ (s,1H,CHO), 7.90 (d, 2H), 7.78-6.80 (m, aromatics, $48 \mathrm{H}), 3.29(\mathrm{t}, 4 \mathrm{H}), 1.70-1.58(\mathrm{~m}, 4 \mathrm{H})$, $1.40(\mathrm{~m}, 4 \mathrm{H}), 2.22\left(\mathrm{~m}, 8 \mathrm{H}, \mathrm{CH}_{2}\right.$ dppe), $1.04(\mathrm{t}, 6 \mathrm{H}) .{ }^{13} \mathrm{C}\left\{{ }^{1} \mathrm{H}\right\}$ NMR $\left(\mathrm{CDCl}_{3}, 125 \mathrm{MHz}, 297 \mathrm{~K}, \delta \mathrm{ppm}\right): 191.5,150.1,149.4$, $148.3\left(\mathrm{q},{ }^{2} J_{\mathrm{P}-\mathrm{C}}=18.7 \mathrm{~Hz}\right), 143.5,142.1,137.0,136.8\left(\mathrm{qt},\left.\right|^{1} J_{\mathrm{P}-\mathrm{C}}+\right.$ ${ }^{3} J_{\mathrm{P}-\mathrm{Cl}}=11 \mathrm{~Hz}, \mathrm{Cq}$, Cipso dppe phenyl), 136.7 (qt, $\mid{ }^{1} J_{\mathrm{P} \_\mathrm{C}}+{ }^{3} J_{\mathrm{P}-\mathrm{C}}$ $=10 \mathrm{~Hz}, \mathrm{Cq}$, Cipso dppe phenyl), 134.3, 134.1, 130.4, 126.6, 124.8, 121.9, 113.6, 111.9, 111.2, 51.0, 31.4, 29.6, 20.4, 14.1. ${ }^{31} \mathrm{P}\left\{{ }^{1} \mathrm{H}\right\}$ NMR $\left(\mathrm{CDCl}_{3}, 81 \mathrm{MHz}, 297 \mathrm{~K}, \delta \mathrm{ppm}\right): 54.1$ (s) Elemental Analysis: $\mathrm{C}_{81} \mathrm{H}_{77} \mathrm{~N}_{3} \mathrm{OP}_{4} \mathrm{SRu}$ (1365.56): calcd: C 71.25, H 5.68, N 3.08, S 2.35; found: C 70.73, H 5.77, N 3.06, S 2.29.

\section{Preparation of spin coated thin films, and optical studies of these films}

High-quality thin films of compounds $\mathbf{2}$ and $\mathbf{3 a , b}$ were made by spin coating of a solution of $\mathbf{2}$ or $\mathbf{3 a}, \mathbf{b}$ (concentration $2-10 \mathrm{wt} \%$ ) in $\mathrm{CH}_{2} \mathrm{Cl}_{2}$ at room temperature using a spinning rate of $300 \mathrm{~min}^{-1}$ for $20 \mathrm{~s}$ and $2500 \mathrm{~min}^{-1}$ for $120 \mathrm{~s}$. These films were subsequently dried at $80^{\circ} \mathrm{C}$ for $1 \mathrm{~h}$. This procedure afforded films with good optical quality having a thickness ranging from 100 to $300 \mathrm{~nm} \pm 10 \mathrm{~nm}$, as measured by using a profilometer Veeco Dektak 6M and a JSM 6301F S. E. M. (C.M.E.B.A.-Centre de Microscopie Electronique à Balayage et microAnalyse at the University of Rennes 1). Absorption spectra on thin layers (300 nm thickness) have been registered on a Perkin Elmer Lambda 19 UV/VIS/NIR spectrometer. Similar procedures were applied for the preparation of PMMA/dye doped films of 2, 3a,b and $N$-ethyl- $N$-hydroxyethyl-4-(4'-nitrophenylazo)phenylamine (DR1), purchased from Aldrich and purified by a double crystallization from an absolute methanol solution. 2, 3a,b and DR1 and PMMA were dissolved in chloroform, filtered with a $250 \mathrm{~nm}$ filter and spin coated on a cleaned glass. The film thickness was measured with a Dektak-6M Stylus Profiler to be $400 \mathrm{~nm}$ and absorption bands ranged from 400 to $600 \mathrm{~nm}$ (see the ESI $\dagger$ ).

The schematic experimental setup for SRG formation is illustrated in the ESI†. The sample film with a thickness of $10-50 \mu \mathrm{m}$ was irradiated with two coherent Nd:YAG laser beams $(532 \mathrm{~nm}, 16 \mathrm{ps}, 10 \mathrm{~Hz})$. The intensity and polarization of these two writing beams were controlled by Glan-Taylor polarizers $(\mathrm{P})$ and half-wave plates $(\lambda / 2)$. Grating formation was monitored by 1st-order diffraction intensities of a probe beam $\mathrm{He}-\mathrm{Ne} \mathrm{cw}$ laser
$(632.8 \mathrm{~nm}, 30 \mathrm{~mW})$ measured in transmission mode (their energy being measured by a photodiode model Centronic Series OSI5). The 1st-order diffraction efficiencies (D.E.) were determined by the ratios of the 1st-order diffraction intensities to the intensity of the incident probe beam.

\section{Acknowledgements}

The authors gratefully acknowledge financial support from the CNRS, the universities of Angers and Rennes 1 for financial support, as well as A.U.F. (Agence Universitaire de la Francophonie) for a grant to R.G. Also, the authors acknowledge the Service Commun d'Imageries et Analyses Microscopiques de l'Université d'Angers for extending AFM facility.

\section{References}

1 K. G. Yager, C. J. Barrett. Azobenzene polymers for photonic applications Smart Light-Responsive Materials, John Wiley \& Sons, Inc., 2009.

2 K. Sumaru, T. Fukuda, T. Kimura, H. Matsuda and T. Yamanaka, J. Appl. Phys., 2002, 91, 3421-3430.

3 D. Gindre, A. Boeglin, A. Fort, L. Mager and K. D. Dorkenoo, Opt. Express, 2006, 14, 9896-9901.

4 D. Gindre, I. Ka, A. Boeglin, A. Fort and K. D. Dorkenoo, Appl. Phys. Lett., 2007, 90, 094103.

5 T. Ikeda and O. Tsutsumi, Science, 1995, 268, 1873-1875.

6 Z. F. Liu, K. Hashimoto and A. Fujishima, Nature, 1990, 347, 658660.

7 B. J. Coe and N. R. M. Curati, Comments Inorg. Chem., 2004, 25, 147-184

8 J. A. G. Williams, Top. Curr. Chem., 2007, 281, 205-268.

9 S. Campagna, F. Puntoriero, F. Nastasi, G. Bergamini and V. Balzani, Top. Curr. Chem., 2007, 280.

10 S. Di Bella, Chem. Soc. Rev., 2001, 30, 355-366.

11 S. Kume and H. Nishihara, Dalton Trans., 2008, 3260-3271.

12 L. Rigamonti, B. Babgi, M. P. Cifuentes, R. L. Roberts, S. Petrie, R. Stranger, S. Righetto, A. Teshome, I. Asselberghs, K. Clays and M. G. Humphrey, Inorg. Chem., 2009, 48, 3562-3572.

13 R. H. Naulty, A. M. McDonagh, I. R. Whittall, M. P. Cifuentes, M. G. Humphrey, S. Houbrechts, J. Maes, A. Persoons, G. A. Heath and D. C. R. Hockless, J. Organomet. Chem., 1998, 563, 137-146.

14 M. Kurihara, A. Hirooka, S. Kume, M. Sugimoto and H. Nishihara, J. Am. Chem. Soc., 2002, 124, 8800-8801.

15 K. Namiki, A. Sakamoto, M. Murata, S. Kume and H. Nishihara, Chem. Commun., 2007, 4650-4652.

16 H. S. Tang, N. Zhu and V. W.-W. Yam, Organometallics, 2007, 26, 22.

17 A. M. McDonagh, N. T. Lucas, M. P. Cifuentes, M. G. Humphrey, S. Houbrechts and A. Persoons, J. Organomet. Chem., 2000, 605, 193-201.

18 D. Y. Kim, L. Li, X. L. Jiang, V. Shivshankar, J. Kumar and S. K. Tripathy, Macromolecules, 1995, 28, 8835-8839.

19 N. J. Long and C. K. Williams, Angew. Chem., Int. Ed., 2003, 42, 2586-2617.

20 C. E. Powell and M. G. Humphrey, Coord. Chem. Rev., 2004, 248, $725-756$

21 J. Luc, K. Bouchouit, R. Czaplicki, J.-L. Fillaut and B. Sahraoui, Opt. Express, 2008, 16, 15633-15639.

22 D. Touchard and P. H. Dixneuf, Coord. Chem. Rev., 1998, 178-180, 409-429.

23 D. Touchard, P. Haquette, S. Guesmi, L. Le Pichon, A. Daridor, L. Toupet and P. H. Dixneuf, Organometallics, 1997, 16, 3640-3648.

24 N. Mantovani, M. Brugnati, L. Gonsalvi, E. Grigiotti, F. Laschi, L. Marvelli, M. Peruzzini, G. Reginato, R. Rossi and P. Zanello, Organometallics, 2005, 24, 405-418.

25 S. Rigaut, J. Perruchon, L. Le Pichon, D. Touchard and P. H. Dixneuf, J. Organomet. Chem., 2003, 670, 37-44.

26 G. Lemercier, M. Alexandre, J.-C. Mulatier and C. Andraud, J. Chem. Res. (S), 2003, 2003, 542-543. 
27 J.-L. Fillaut, J. Perruchon, P. Blanchard, J. Roncali, S. Golhen, M. Allain, A. Migalska-Zalas, I. V. Kityk and B. Sahraoui, Organometallics, 2005, 24, 687-695.

28 W. B. Austin, N. Bilow, W. J. Kelleghan and K. S. Y. Lau, J. Org. Chem., 1981, 46, 2280-2286.

29 C. E. Powell, M. P. Cifuentes, J. P. Morrall, R. Stranger, M. G. Humphrey, M. Samoc, B. Luther-Davies and G. A. Heath, J. Am. Chem. Soc., 2003, 125, 602-610.

30 J.-L. Fillaut, J. Andriès, J. Perruchon, J.-P. Desvergne, L. Fadel, B. Zouchoune and J.-Y. Saillard, Inorg. Chem., 2007, 46, 5922-5932.

31 C. E. Powell, M. P. Cifuentes, A. M. McDonagh, S. K. Hurst, N. T. Lucas, C. D. Delfs, R. Stranger, M. G. Humphrey, S. Houbrechts, I. Asselberghs, A. Persoons and D. C. R. Hockless, Inorg. Chim. Acta, 2003, 352, 9-18.
32 S. Rau. Photochemistry and Photophysics, CRC Press, Boca Raton, 1990, Vol. III.

33 C. J. Barrett, J.-i. Mamiya, K. G. Yager and T. Ikeda, Soft Matter, 2007, 3, 1249-1261.

34 R. Czaplicki, O. Krupka, Z. Essaïdi, A. El-Ghayoury, F. Kajzar, J. G. Grote and B. Sahraoui, Opt. Express, 2007, 15, 1526815273.

35 K. G. Yager and C. J. Barrett, J. Chem. Phys., 2007, 126, 094908.

36 E. Ishow, R. Camacho-Aguilera, J. Guérin, A. Brosseau and K. Nakatani, Adv. Funct. Mater., 2009, 19, 796-804.

37 A. S. Kumar, T. Ye, T. Takami, B.-C. Yu, A. K. Flatt, J. M. Tour and P. S. Weiss, Nano Lett., 2008, 8, 1644-1648.

38 G. Vives and J. M. Tour, Tetrahedron Lett., 2009, 50, $1427-$ 1430. 